\title{
Mallas de paisanaje: el entramado de relaciones de los inmigrantes
}

\author{
Isidro Maya Jariego ${ }^{1}$ - Universidad de Sevilla
}

\section{Resumen}

Este artículo resume una parte de nuestro trabajo sobre las redes de apoyo social de los inmigrantes. En él se combina una recopilación de algunos de los resultados de investigación más significativos con la formulación de argumentos de carácter hipotético, aunque basados en las evidencias previas. Para ello desarrollamos tres contenidos fundamentales. Primero, presentamos brevemente el concepto de apoyo social. En segundo lugar, revisamos - con población inmigrante- algunas de las dimensiones de dicho concepto, tales como la multiplicidad de los proveedores, los intercambios de ayuda, el contexto colectivo de las cadenas migratorias, etcétera. Finalmente, en tercer lugar, proponemos una clasificación de los tipos de redes de apoyo de los inmigrantes con menos de diez años de residencia en España.

Palabras clave: Apoyo social - Inmigrantes - Redes personales.

\section{Abstract}

This paper summarises part of our work concerning social support networks among immigrants. It combines a compilation of some of our most significant findings with the formulation of hypothetical arguments that are based on previous evidence. We shall develop three main points: first, we shall briefly present the concept of social support; second, we shall review-with immigrant populations-some dimensions of this concept, such as the multiplicity of providers, help exchanges, and the collective context of migration chains; finally, we shall propose a classification of the types of support chains involving immigrants with less than ten years of residence in Spain.

Key words: Social Support - Immigrants - Personal networks.

Los estudios migratorios han recurrido al concepto de red social para representar los flujos de población entre países y la incorporación de los inmigrantes en el nuevo contexto receptor. En este caso la idea de red pretende capturar los patrones de interacción de los individuos que se desplazan, para determinar su influencia entre otros aspectos- en la decisión de emigrar, la reubicación geográfica, el reagrupamiento familiar, la formación de comunidades de compatriotas, el proceso de aculturación, la adaptación psicológica y la integración social.

\footnotetext{
${ }^{1}$ Correspondencia con el autor: <isidromj@us.es>. Este artículo se publicó previamente en una monografía sobre migraciones y ha sido publicado con el permiso del editor: Maya Jariego, I. (2006). Mallas de paisanaje: el entramado de relaciones de los inmigrantes. En Pérez Pont, J. L. (Ed.). Geografías del desorden. Migración, alteridad y nueva esfera social, 257-276. Universidad de Valencia: Valencia.
} 
REDES- Revista hispana para el análisis de redes sociales

Vol.17,\#13, Diciembre 2009

http://revista-redes.rediris.es

Los dos temas en los que se ha desarrollado una literatura más amplia sobre las redes sociales de la población inmigrante son las cadenas migratorias y la adaptación psicológica:

La emigración en cadena es un proceso de desplazamiento y reubicación de redes de familiares, amigos y conocidos. Las cadenas influyen en la toma de decisiones previa al desplazamiento internacional y en el proceso de asentamiento posterior. Por ejemplo, el emplazamiento de parientes y amigos condiciona la elección del lugar de destino; mientras que la madurez de la cadena migratoria define de algún modo la estructura de oportunidades de las relaciones interpersonales (tanto para el desarrollo como para el mantenimiento de contactos).

Las redes de apoyo social proporcionan recursos que facilitan el proceso de adaptación. En las relaciones interpersonales de los inmigrantes recién llegados se intercambia información y ayuda instrumental que sirven para manejarse en un entorno desconocido. Del mismo modo, disponer de confidentes y de apoyo afectivo es una condición necesaria para el bienestar psicológico subjetivo. La integración social y las relaciones de apoyo promueven la salud y contribuyen al afrontamiento de circunstancias estresantes.

Como vemos, las redes de apoyo social ayudan a entender las dinámicas del desplazamiento internacional, tanto en lo que se refiere a los flujos migratorios como al proceso de integración social en los lugares de destino. Las redes de apoyo permiten combinar las perspectivas micro y macro, y pueden integrar la literatura de las cadenas migratorias con la investigación sobre la adaptación psicológica de los inmigrantes.

Este artículo resume una parte de nuestro trabajo sobre las redes de apoyo social de los inmigrantes. En él se combina una recopilación de algunos de los resultados de investigación más significativos con la formulación de argumentos de carácter hipotético, aunque basados en las evidencias previas2.

Para ello desarrollamos tres contenidos fundamentales. Primero, presentamos brevemente el concepto de apoyo social. En segundo lugar, revisamos -con población inmigrante- algunas de las dimensiones de dicho concepto, tales como la multiplicidad de los proveedores, los intercambios de ayuda, el contexto colectivo de las cadenas migratorias, etcétera. Finalmente, en tercer lugar, proponemos una

\footnotetext{
${ }^{2}$ La investigación a la que me refiero en este artículo corresponde a estudios realizados a lo largo de más de una década. Sin embargo, su contenido se ha beneficiado especialmente de mis conversaciones más recientes con Neil Armitage, Ainhoa de Federico, Alexis Ferrand, Daniel Holgado, Carlos Lozares, Christopher McCarty y José Luis Molina. A todos ellos mi agradecimiento.
} 
REDES- Revista hispana para el análisis de redes sociales

Vol.17,\#13, Diciembre 2009

http://revista-redes.rediris.es

clasificación de los tipos de redes de apoyo de los inmigrantes con menos de diez años de residencia en España.

Pero antes de entrar en cada uno de estos contenidos veamos tres ejemplos concretos de redes personales de extranjeros residentes en España. Estos tres casos van a servir para ilustrar cómo varían las redes de los inmigrantes, dando introducción de ese modo a nuestro objeto de análisis en los siguientes apartados.

Rosa, Estela y Max: tres casos de redes personales de inmigrantes

La representación de las redes personales pretende capturar la estructura de las redes de parentesco, conocimiento y amistad en torno a cada individuo. A continuación, analizamos brevemente los casos de tres extranjeros residentes en Andalucía. Los grafos representan los lazos fuertes entre el conjunto de proveedores de apoyo y de conocidos mencionados por cada entrevistado. Tomamos en consideración el tamaño, la estructura, la composición y la multiplicidad. Cada gráfico sigue las siguientes pautas3:

El entrevistado no aparece en el sociograma. Lo que se muestran son las relaciones entre el listado de personas que el entrevistado ha citado como amigos, familiares y conocidos.

Los lazos entre nodos reflejan que dos personas se conocen mucho entre sí.

En amarillo se representan los compatriotas de cada entrevistado, y en verde los españoles.

El tamaño del nodo corresponde al número de tipos de ayuda que dicho vínculo proporciona al entrevistado. De modo que los nodos más gruesos son los proveedores de apoyo más importantes.

Hemos elegido a extranjeros de tres nacionalidades diferentes, con cierta diferencia en el tiempo de residencia en España y en sus condiciones de vida, de modo que nos permita mostrar la diversidad de redes personales.

Caso 1, ecuatoriana, 33 años

Rosa es una ecuatoriana que lleva tres años residiendo en Sevilla. Vive en un piso compartido con otros seis inmigrantes recientes: su marido, que emigró después que ella, cuatro compatriotas y una boliviana. Rosa mantiene contacto habitual con su madre y sus seis hijos, que viven en Ecuador, y según comenta en la entrevista "se apoya en su marido para todo".

\footnotetext{
${ }^{3}$ Una descripción detallada y una justificación del procedimiento de estudio y representación de las redes personales puede encontrarse en la literatura citada en la bibliografía.
} 
REDES- Revista hispana para el análisis de redes sociales

Vol.17,\#13, Diciembre 2009

http://revista-redes.rediris.es

Se trata de una red personal mínima, densa y homogénea. Con la excepción de María - la inmigrante boliviana que trabaja con ella en la limpieza a domicilio, y con la que también comparte piso- todas las personas a las que menciona son paisanos. El único proveedor de ayuda polivalente es su marido. Más de la mitad de su red son familiares residentes en Ecuador, con los que mantiene contacto por teléfono dos veces al mes.

La formación de pequeños grupos de compatriotas es una de las estrategias de socialización que los inmigrantes recientes siguen en el país de destino. Asociarse con otras personas que se encuentran en la misma situación da respuesta a la necesidad de contacto y sociabilidad, al mismo tiempo que permite compartir los gastos de vivienda.

No obstante, parece razonable pensar que la emigración ha afectado negativamente a la disponibilidad de apoyo de Rosa, que apenas se ve rodeada por un pequeño grupo de compatriotas y que se ha visto forzada a concentrar las demandas de ayuda en su marido.

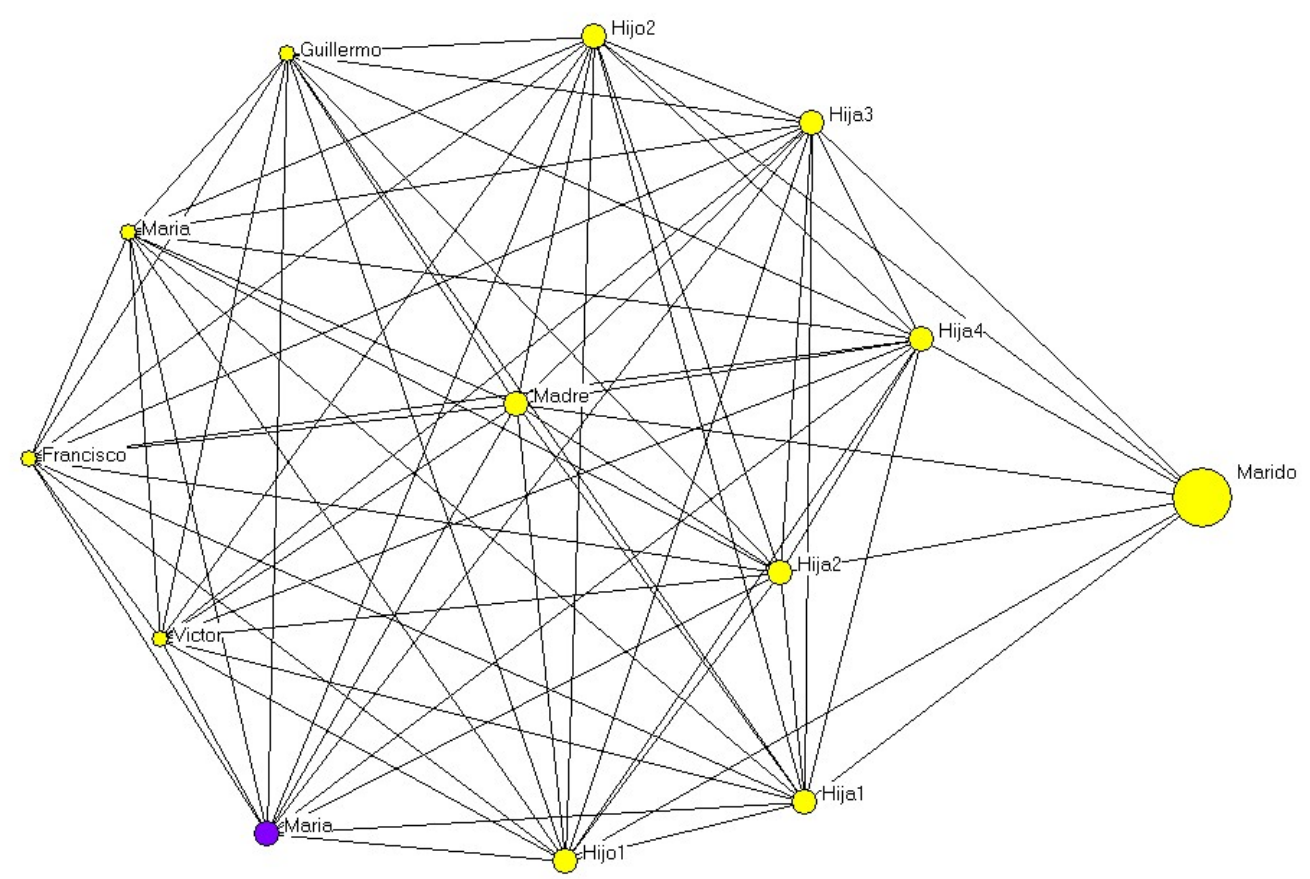

Caso 1. Rosa, ecuatoriana con 3 años de residencia en Sevilla.

\section{Caso 2, argentina, 44 años}

Estela es argentina y lleva seis años y medio viviendo en Cádiz. Trabaja de cocinera en un restaurante y participa en cinco asociaciones. Casi la mitad de los contactos que menciona son españoles: se trata del propietario del restaurante, cuatro conocidos de una asociación y una amiga. 
REDES- Revista hispana para el análisis de redes sociales

Vol.17,\#13, Diciembre 2009

http://revista-redes.rediris.es

La parte más significativa de su red de apoyo son tres amigas argentinas - Isabel, Beatriz y Carola-, su hermano Adrián, y Maica, una amiga española. El hijo de Estela tiene una posición central en su red personal, puesto que conoce a todos los miembros de la misma, pero no es un proveedor activo de apoyo.

También mantiene contacto por teléfono y por correo electrónico, unas dos veces al mes, con dos hermanos y una amiga argentinos.

A simple vista, la red personal de Estela difiere claramente del caso anterior, en primer lugar, en la composición por nacionalidades. Estela ha desarrollado relaciones con españoles en su lugar de trabajo - concretamente, con su jefe- y en una asociación, con tres conocidos. Además, menciona una amiga española. El mundo asociativo y el mundo del trabajo son ámbitos de socialización con la comunidad local, que a medio plazo pueden traducirse en la formación de relaciones de amistad.

En segundo lugar, la red personal de Estela también se caracteriza -en comparación con la de Rosa- por una mayor distribución de las fuentes de apoyo. Mientras que en el caso de Rosa el único rol destacado correspondía al marido, Estela cuenta con cuatro amigas y un hermano como proveedores polivalentes de ayuda en España.

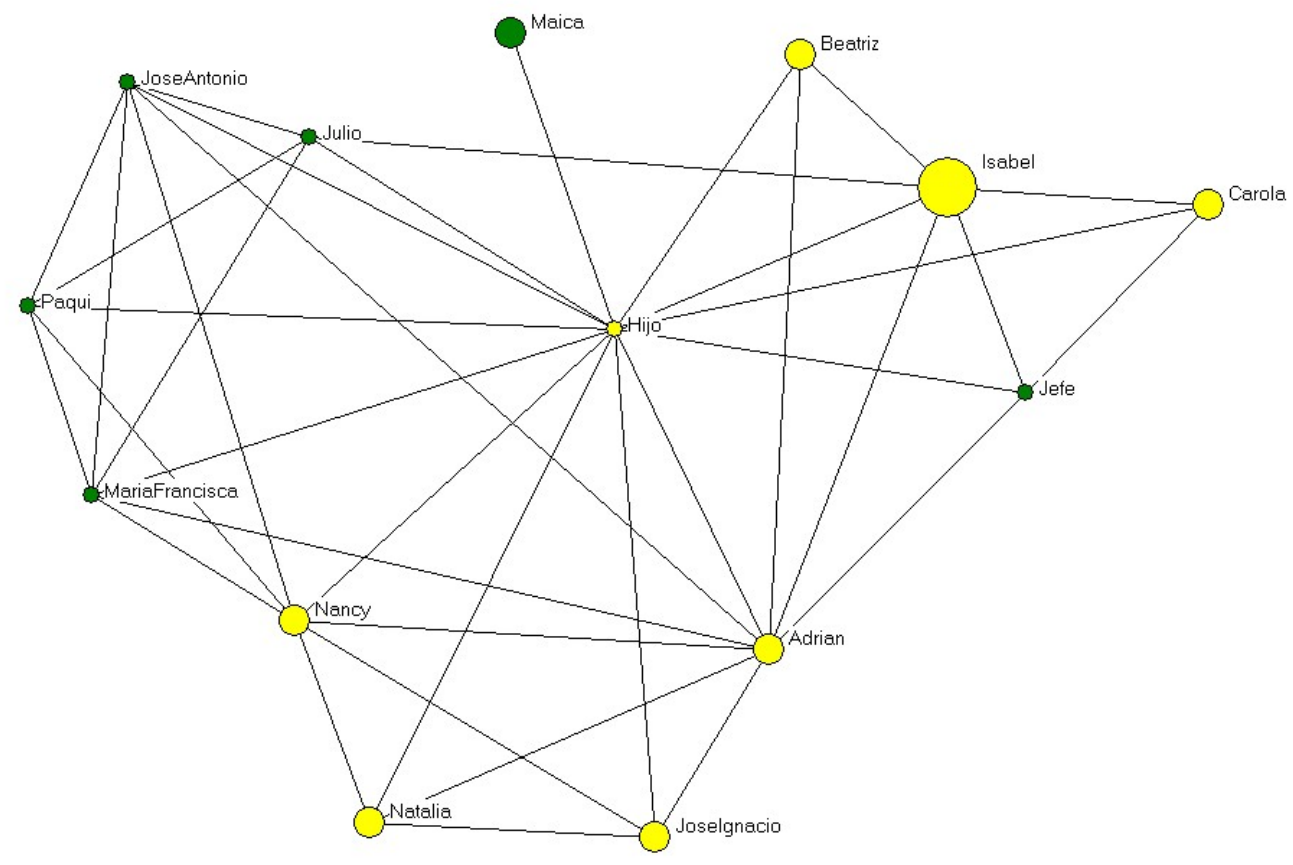

Caso 2. Estela, argentina con 6 años y medio de residencia en Cádiz. 
REDES- Revista hispana para el análisis de redes sociales

Vol.17,\#13, Diciembre 2009

http://revista-redes.rediris.es

\section{Caso 3, italiano, 36 años}

Max es italiano4 y trabaja desde hace 5 años en un servicio de una institución europea en Sevilla. Vive con su novia, también de origen italiano. Sus relaciones se dividen en tres grupos bien definidos: un grupo de amigos españoles del gimnasio que frecuenta, un grupo de amigos españoles de su lugar de trabajo y un grupo de cuatro personas con las que mantiene contacto en Italia.

La novia de Max tiene un papel central, articulador, en su red personal, puesto que está conectada con los tres grupos de su red y con dos de los actores clave de la misma. Tres de los amigos españoles de Max tienen el rol de proveedores polivalentes de ayuda, es decir, son vínculos sinérgicos. Además, mantiene contacto casi a diario por teléfono y por correo electrónico con sus padres y con dos amigos italianos.

La composición de la red personal es una combinación de españoles e italianos. Pero en este caso destaca el hecho de que dos tercios de los contactos son españoles. Además, los españoles también son mayoría entre los proveedores de apoyo más polivalentes. Con la excepción de su novia, de origen italiano, el resto de vínculos sinérgicos son españoles: amigos del gimnasio o de su lugar de trabajo. La red personal de Max parece reflejar un proceso de asimilación social bastante desarrollado, con una incorporación decidida en la comunidad local. Este hecho se observa tanto en la composición de la red personal (con una mayor presencia de españoles) como en la multiplicidad de los proveedores (con más relaciones polivalentes de la sociedad receptora).

\footnotetext{
${ }^{4}$ A los residentes de otros países de la Unión Europea, como es el caso, no suele aplicárseles la categoría "inmigrante". Sin embargo, el proceso básico de desplazamiento internacional, aculturación y adaptación psicológica es el mismo. Difieren las condiciones institucionales y las actitudes de la población receptora, entre otras cuestiones, pero para nuestros objetivos de análisis se trata de un caso válido, que introduce una perspectiva comparada interesante.
} 
REDES- Revista hispana para el análisis de redes sociales

Vol.17,\#13, Diciembre 2009

http: // revista-redes.rediris.es

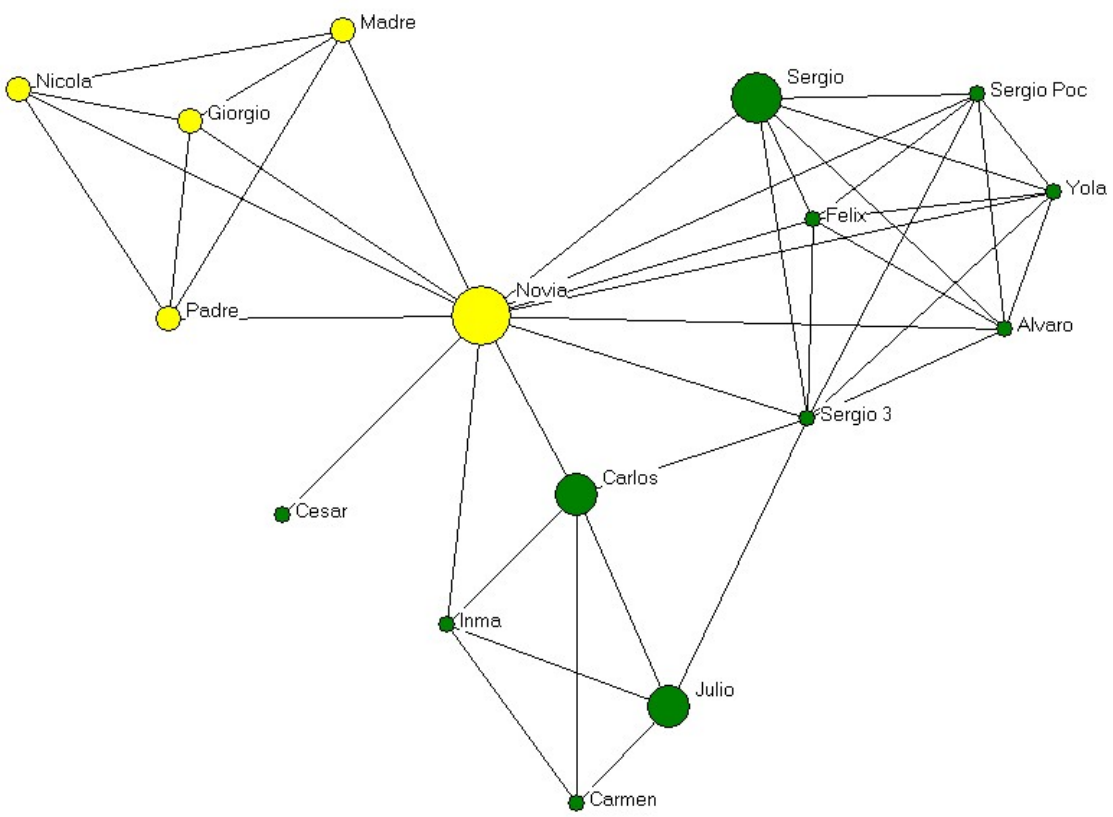

Caso 3. Max, italiano con 5 años de residencia en Sevilla.

También es llamativa la estructura abierta de la red, que se divide en tres espacios bastante definidos: el grupo del trabajo, los amigos del gimnasio y los padres y amigos de Italia. En comparación con el Caso 1, que es una red personal densa y cohesionada, Max dispone de una red con un mayor nivel de intermediación promedio5.

Las tres redes de apoyo que hemos mostrado varían en tamaño, composición, estructura y multiplicidad de los proveedores de apoyo. De modo resumido, podemos destacar las siguientes diferencias:

Composición. La red personal de Rosa (Caso 1) es la más homogénea en composición, mientras que las redes de Estela y Max están compuestas, en distinto grado, por compatriotas y españoles. Podemos formular la hipótesis de que la emigración aumenta las oportunidades de contacto con miembros de otros colectivos, haciendo de algún modo más probables los cambios en la composición de acuerdo con el tiempo de estancia en el lugar de acogida.

Estructura. La red personal de Rosa (Caso 1) es la más densa y cohesionada, mientras que las de Estela y Max cuentan con subgrupos más o menos definidos, con mayor grado de intermediación promedio. Podemos suponer que el proceso de aculturación conlleva cambios en la composición, que se reflejan también en las propiedades estructurales de la red personal. Quizás los indicadores sobre el grado

\footnotetext{
${ }^{5}$ Average betweeness.
} 
REDES- Revista hispana para el análisis de redes sociales

Vol.17,\#13, Diciembre 2009

http://revista-redes.rediris.es

de intermediación pueden servir entonces como aproximación empírica al proceso de aculturación.

Multiplicidad. Los tres casos varían en la distribución de las fuentes de apoyo. Por un lado, en la red de Rosa (Caso 1) la disponibilidad de ayuda percibida se concentra preferentemente en un actor, el marido, mientras que en las de Estela y Max hay al menos cuatro proveedores polivalentes de ayuda bastante destacados. Por otro lado, podemos tomar en consideración cómo se distribuye la multiplicidad entre los distintos grupos nacionales: en este caso, Max (Caso 3) es el que cuenta con proveedores más distribuidos entre grupos, mostrando su mayor inserción en la sociedad española. Podemos formular la hipótesis de que el proceso de asimilación social en un colectivo determinado se refleja en la distribución de la multiplicidad entre los actores de diferentes círculos sociales. Quizás la proporción de vínculos polivalentes con españoles puede servir entonces como aproximación empírica al proceso de asimilación social en la comunidad local.

Tamaño. No hay grandes diferencias de tamaño en los tres casos analizados. Las redes personales de Rosa, Estela y Max cuentan, respectivamente, con 13, 14 y 16 actores. Sin embargo, se observan diferencias en el núcleo central de proveedores de apoyo. Los vínculos que proporcionan tres o más tipos de ayuda son, respectivamente, 1,5 y 4 . Pese a la diversidad de trayectorias personales, podemos formular la hipótesis de que la emigración es un proceso de reconstrucción de la red personal, donde el tamaño se recupera, de algún modo, de acuerdo con el tiempo de estancia en el lugar de acogida (y después de un claro descenso inicial de los recursos de apoyo disponibles).

Como acabamos de comprobar, las redes de apoyo pueden examinarse desde diferentes puntos de vista, y cuentan con diversas dimensiones susceptibles de análisis. Antes de entrar en más detalles sobre las redes de apoyo social de los inmigrantes, nos detendremos en clarificar el concepto de apoyo social.

Las redes de apoyo social

El término "apoyo social" se aplica a conductas, personas, transacciones y sistemas sociales. Se trata de un concepto que comprende múltiples dimensiones de las relaciones sociales. Por eso es necesario definirlo separando sus componentes específicos, como vamos a hacer a continuación. El esquema conceptual que seguimos está representado en la Figura 1.

Una de las distinciones más básicas consiste en diferenciar la integración social, la estructura de la red social y los contenidos relacionales: 
REDES- Revista hispana para el análisis de redes sociales

Vol.17,\#13, Diciembre 2009

http://revista-redes.rediris.es

La integración social tiene que ver con la mera existencia y cantidad de lazos sociales. Es decir, se trata de una dimensión que distingue la soledad y el aislamiento de los diferentes niveles de integración. Puede evaluarse con el tamaño de la red, el número de familiares y amigos, la frecuencia de contacto o el número de roles importantes que una persona desarrolla.

La estructura de la red social se refiere a la distribución y organización de los lazos sociales. La estructura del conjunto de relaciones puede representarse, por ejemplo, con indicadores sobre la densidad, la centralidad y la agrupación de los actores. También puede informarse indirectamente de la composición, la reciprocidad y la multiplicidad de las relaciones.

Finalmente, el apoyo social es uno de los contenidos funcionales de las relaciones sociales. El apoyo social hace referencia a aspectos positivos de las relaciones -en concreto, la ayuda instrumental, la provisión de afecto o la información-, que potencialmente tienen efectos de promoción del bienestar psicológico y de amortiguamiento del estrés. Pero las relaciones también originan disputas, preocupaciones y funciones de control social.
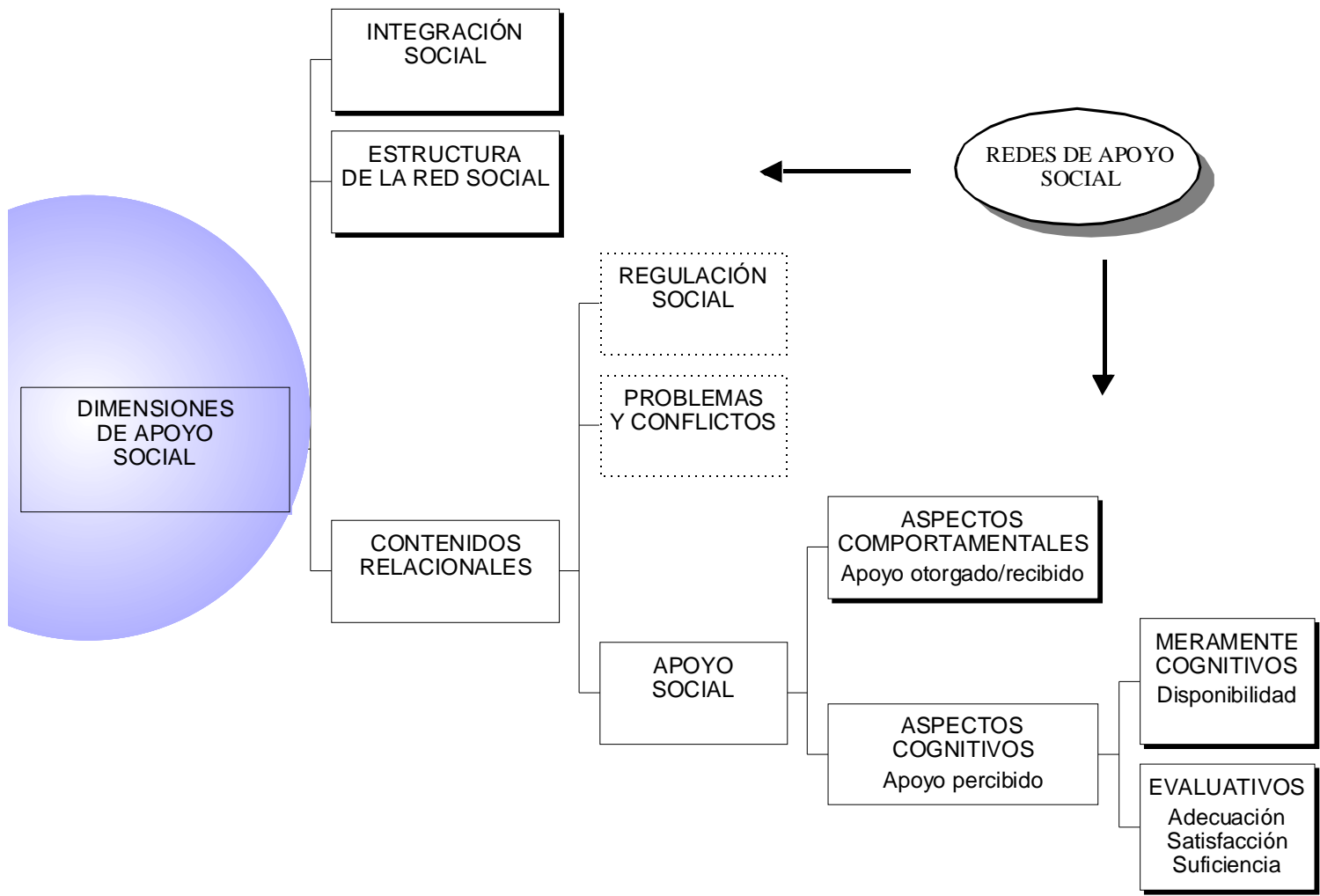

Figura 1. Dimensiones del "apoyo social". 
REDES- Revista hispana para el análisis de redes sociales

Vol.17,\#13, Diciembre 2009

http://revista-redes.rediris.es

Integración, estructura y contenidos funcionales se solapan en cierta medida. Las propiedades estructurales de la red presuponen la integración social. Del mismo modo, el apoyo - o cualquiera de los otros contenidos funcionales- presupone la estructura y la integración social. Cuando utilizamos el concepto de "redes de apoyo social", generalmente nos referimos al subconjunto de la red personal del individuo que proporciona información, ayuda instrumental y apoyo afectivo. En consecuencia, las funciones, la estructura y los niveles de integración están implicados simultáneamente.

Una segunda distinción es la que se refiere a los aspectos cognitivos y comportamentales del apoyo. El apoyo percibido es de naturaleza cognitiva y tiene que ver con las valoraciones subjetivas que hace el individuo sobre la funcionalidad de su entorno personal inmediato. Una forma de evaluarlo consiste, por ejemplo, en preguntarle al individuo por las personas que considera disponibles en el caso de que necesite ayuda, consejo o información. Por su parte, el apoyo recibido es de carácter conductual, y hace referencia a comportamientos de ayuda que han ocurrido de hecho. Por ejemplo, podemos contabilizar la ayuda material que recibió una persona durante el último mes.

Además, dentro del apoyo percibido es posible distinguir las dimensiones de naturaleza meramente cognitiva -como es la percepción de disponibilidad de apoyo- de aquellas en las que se introduce, además, un componente evaluativo por parte de la persona, tales como la satisfacción, la adecuación y la suficiencia atribuidas al entorno interpersonal inmediato.

En suma, hemos identificado al menos cinco conceptos diferentes que pueden ser tratados analíticamente por separado: (1) la inserción social, (2) la estructura de la red social, (3) los intercambios de ayuda (es decir, el apoyo recibido y otorgado), (4) la percepción de apoyo disponible y (5) la valoración sobre la adecuación del apoyo. El apoyo social, evidentemente, implica a todos ellos. Sin embargo, los matices conceptuales son necesarios para depurar y mejorar la investigación sobre el tema.

Pensemos por un momento en el caso de los inmigrantes. ¿Cuáles son las consecuencias del desplazamiento internacional? ¿Disminuye el nivel de conectividad social tras la reubicación? ¿Influye de modo diferente la emigración en la estructura y las funciones de apoyo? ¿De qué modo afecta el hecho de mudarse a otro país a los intercambios de ayuda y a la percepción de apoyo disponible? ¿Se mantienen los lazos con el lugar de origen? ¿De qué modo se reconstruyen las 
REDES- Revista hispana para el análisis de redes sociales

Vol.17,\#13, Diciembre 2009

http://revista-redes.rediris.es

redes sociales en el lugar de destino? ¿Qué cambios se observan en la composición de las redes personales?

Las múltiples dimensiones del apoyo social nos ayudan a entender los cambios que experimentan los inmigrantes en sus relaciones interpersonales. Veamos brevemente a continuación qué sabemos sobre el tema.

\section{La investigación sobre las redes de apoyo de los inmigrantes}

La reconstrucción de las redes de apoyo social de los inmigrantes internacionales ha sido descrita prestando especial atención a los cambios en el tamaño y la composición de las mismas. En algún caso, se han estudiado también las peculiaridades culturales de determinados grupos étnicos desplazados. Los tres temas de investigación más habituales han consistido en:

Evaluar el impacto del desplazamiento en la cantidad de apoyo disponible.

Contrastar la composición mayoritariamente familiar de las redes de los individuos que provienen de culturas tradicionales; y

Detallar los cambios que experimenta el entorno personal del inmigrante en el nuevo contexto receptor a lo largo del tiempo.

En primer lugar, la emigración parece afectar al tamaño de la red de apoyo6. Los inmigrantes recientes tienen menos disponibilidad de ayuda que la población autóctona. Este hecho se observa, además, en diferentes poblaciones y contextos. Por poner algunos ejemplos, se ha documentado con inmigrantes mexicanos y centroamericanos en Estados Unidos, con inmigrantes asiáticos en Reino Unido, con inmigrantes latinoamericanos y africanos en España, e incluso con las migraciones internas de temporada en Estados Unidos. Se trata de una conclusión importante, puesto que el tamaño de la red de apoyo es una dimensión fundamental, con importantes repercusiones en el proceso de adaptación, y que correlaciona con todas las demás variables de apoyo. Volveremos sobre este tema más adelante.

La segunda línea de investigación pone de manifiesto la existencia de redes de ayuda formadas mayoritariamente por familiares. En muchas de las sociedades de procedencia de los inmigrantes es habitual la estructura de familia extensa. Es el caso, por ejemplo, de los asiáticos, los latinoamericanos y los africanos asentados en Estados Unidos y en Europa. Los comportamientos de ayuda entre inmigrantes como proporcionar alojamiento y ayudar a encontrar un trabajo- reflejan a veces la

\footnotetext{
${ }^{6}$ Mientras que en los estudios con población general se obtiene una media de proveedores de entre 10 y 11, con diferentes poblaciones de inmigrantes se observan promedios que oscilan entre 4 y 8 proveedores de apoyo social.
} 
REDES- Revista hispana para el análisis de redes sociales

Vol.17,\#13, Diciembre 2009

http: // revista-redes.rediris.es

obligación económica recíproca entre los miembros de la familia extensa. La comparación entre mexicanos y anglosajones en Estados Unidos muestra que los primeros tienen más familiares y menos amigos en sus redes personales, y que desarrollan también una mayor frecuencia de contacto con los familiares. Todo esto es especialmente significativo si tenemos en cuenta que los parientes cercanos tienen un gran impacto en la calidad de vida de los inmigrantes.

Sin embargo, las redes de parentesco obedecen en parte a la estructura de oportunidades que los inmigrantes encuentran en el contexto receptor. Por ejemplo, la composición más o menos familiar parece depender del tiempo de estancia, el grado de reagrupamiento familiar, la generación migratoria y el tamaño de las comunidades de compatriotas inmigrantes, entre otros factores. Por eso es necesario tener en cuenta los cambios que se producen a lo largo del tiempo. Ese es el tercero de los temas que nos ocupan.

Generalmente se produce un crecimiento paulatino de la red de apoyo a lo largo del tiempo. En el primer período de asentamiento el entorno personal de ayuda suele ser pequeño, compuesto mayoritariamente por familiares y compatriotas, con una elevada frecuencia de contacto con ambos grupos. Posteriormente se empiezan a incorporar miembros de la sociedad de acogida. Parece, por tanto, que al mismo tiempo que la red de apoyo gana en tamaño su composición se hace más diversa. Veamos algunos casos para ilustrar este proceso.

En el colectivo de inmigrantes polacos recién llegados a Estados Unidos se ha observado un curioso fenómeno de segmentación de las funciones instrumentales y emocionales de la red personal. La principal fuente de apoyo afectivo son otros paisanos de la misma oleada migratoria, mientras que los proveedores de apoyo instrumental e informativo son polacos que habían llegado antes. Ese tipo de "segmentación" no es habitual en la población general, que suele contar con un círculo cercano de familiares y amigos que proporcionan todos los tipos de ayuda. En los primeros momentos de reasentamiento es cuando el inmigrante tiene más necesidad de ayuda y menos posibilidades de obtenerla. En esos momentos son cruciales las relaciones con otros compatriotas. Los inmigrantes de la misma oleada son sobre todo un soporte afectivo, en parte porque carecen de recursos materiales que intercambiar con sus iguales. Como alternativa, la ayuda tangible se obtiene de compatriotas de oleadas anteriores, en parte también porque se parecen menos entre sí, y son en consecuencia menos idóneos para proporcionar apoyo emocional.

Las trayectorias personales son muy diversas. Pero después de esta fase de concentración de las demandas de ayuda en un pequeño grupo de compatriotas, la 
REDES- Revista hispana para el análisis de redes sociales

Vol.17,\#13, Diciembre 2009

http://revista-redes.rediris.es

dinámica habitual es de expansión y crecimiento de los contactos personales. En el caso de las mujeres inmigrantes en Canadá se ha constatado una sucesión de tres pasos. Primero los contactos se limitan a los familiares más cercanos, y quizás a alguna relación de amistad íntima. A medio plazo este círculo tan reducido no es suficiente para responder a las necesidades de las mujeres. A continuación, las relaciones se extienden a miembros de la comunidad étnica y religiosa, con los que se comparten valores y con los que es más fácil la comunicación. Finalmente se desarrollan relaciones con miembros de la sociedad de acogida. Esto sirve para evitar el sentimiento de segregación y permite contar con algún confidente externo a los grupos en los que habitualmente se participa, manteniendo así el sentimiento de privacidad.

El mismo fenómeno se comprueba con los refugiados salvadoreños en Canadá. Como no existe una comunidad de salvadoreños amplia y estructurada, la vida social del recién llegado se limita prácticamente a la familia. Después algunas actividades deportivas y de ocio permiten establecer contacto con otros compatriotas. Las relaciones con canadienses empiezan a desarrollarse en el lugar de trabajo y son más fáciles para aquellos que dominan el idioma.

En resumen, la red personal es un sistema dinámico: como hemos comprobado, se transfigura con el traslado, dando lugar a un nuevo mapa de relaciones, que es una mezcla de miembros de la antigua red, personas que se han trasladado juntos (con frecuencia, el grupo familiar) y nuevos miembros que se incorporan cuando la situación lo permite. Pero mientras se configura este nuevo entorno, algunas necesidades pueden dejar temporalmente de estar cubiertas. Pensemos por ejemplo en el caso de familias emigrantes: cada uno de los miembros puede echar de menos la parte de su red personal que dejó atrás, y a su vez pueden sentirse sobrecargados por el aumento de las demandas de ayuda por parte de familiares que se da como consecuencia de lo anterior. El reagrupamiento familiar y la incorporación de miembros de la sociedad local son dos procesos básicos en la reconstrucción y la reorganización de la red personal en sus sucesivas fases.

Esta representación coincide a grandes rasgos con nuestra investigación de las redes de apoyo de los inmigrantes africanos y latinoamericanos en España. En la Tabla 1 se resumen algunos de los datos más significativos de los estudios que hemos desarrollado en los últimos 13 años. Aunque en la mayoría de los casos se trata de inmigrantes recientes en España, también se incluye alguna encuesta aplicada en Argentina. 
REDES- Revista hispana para el análisis de redes sociales

Vol.17,\#13, Diciembre 2009

http: //revista-redes.rediris.es

El tamaño de las redes de apoyo oscila entre los 4 y los 11 vínculos en promedio, estando la media teórica en 7.7 proveedores. Los compatriotas representan aproximadamente, pese a las fluctuaciones propias del tipo de población, dos tercios del total de la red de apoyo. Por tanto, se observan redes de apoyo de un tamaño inferior al que se obtiene en encuestas a la población general, que giran en torno a los 10 miembros en promedio. También son redes bastante homogéneas, donde predomina la presencia de compatriotas inmigrantes. No obstante, se observan espacios de contacto con la población receptora, que introducen diversidad en la composición.

Los inmigrantes ven afectadas sus redes de apoyo tras el desplazamiento. En primer lugar, se reduce la disponibilidad de proveedores activos de apoyo. Lo más habitual es contar con un pequeño grupo de familiares y compatriotas, en un número que oscila entre 4 y 7 . Esta limitación inicial de las oportunidades de contacto lleva a que se intente sacar el máximo partido a los recursos disponibles. Por ejemplo, se forman pequeñas agrupaciones de compatriotas inmigrantes, que enfrentan una situación parecida. Además, las demandas de ayuda se concentran en los vínculos disponibles, que ganan en multiplicidad. Por ejemplo, un amigo íntimo, un hermano o la pareja pueden cubrir todas las necesidades de la persona cuando el resto de contactos son puntuales o muy limitados. Esto hace que en ocasiones no se cuente con una estructura de apoyo suficiente. Pueden darse casos en los que se depende de un proveedor para resolver los problemas de la vida diaria, mientras que en otros las necesidades se quedan sin ser cubiertas. 
REDES- Revista hispana para el análisis de redes sociales

Vol.17,\#13, Diciembre 2009

http://revista-redes.rediris.es

\begin{tabular}{|c|c|c|}
\hline Referencia & Población & Redes de apoyo \\
\hline $\begin{array}{l}\text { Maya J ariego et al. } \\
\text { (2005) }\end{array}$ & $\begin{array}{l}\text { Argentinos ( } n=67) \text {, ecuatorianos } \\
\text { (59), alemanes (37) e italianos ( } 37 \text { ) } \\
\text { residentes en Sevilla y Cádiz. }\end{array}$ & $\begin{array}{l}\text { Tamaño: } 10.74 \text {, con una } \\
\text { composición de dos tercios de } \\
\text { compatriotas. El tamaño oscila } \\
\text { entre } 8.5 \text { en los ecuatorianos y } \\
14.8 \text { en los alemanes. }\end{array}$ \\
\hline $\begin{array}{l}\text { Tonón \& Maya Jariego } \\
\text { (2006) }\end{array}$ & $\begin{array}{l}\text { Marroquíes en España }(n=59) \text {, y } \\
\text { paraguayos ( } 25) \text { y bolivianos (19) en } \\
\text { Argentina. }\end{array}$ & $\begin{array}{l}\text { Índice de apoyo otorgado/recibido: } \\
0.88\end{array}$ \\
\hline $\begin{array}{l}\text { Maya Jariego \& de la } \\
\text { Vega (2004) }\end{array}$ & $\begin{array}{l}\text { Muestra representativa de } 209 \text { indios } \\
\text { de primera y segunda generación } \\
\text { residentes en Salta y Buenos Aires } \\
\text { (Argentina) }\end{array}$ & $\begin{array}{l}\text { Tamaño: } 10.64, \text { con menos de un } \\
25 \text { por ciento de compatriotas }\end{array}$ \\
\hline $\begin{array}{l}\text { Martínez, García \& Maya } \\
\text { Jariego (2000) }\end{array}$ & $\begin{array}{l}\text { Un total de } 123 \text { inmigrantes africanos } \\
\text { y latinoamericanos participantes en el } \\
\text { programa Horizon. }\end{array}$ & $\begin{array}{l}\text { Tamaño: } 6.85 \text {, con un } 70 \text { por } \\
\text { ciento de compatriotas }\end{array}$ \\
\hline García et al. (2005) & $\begin{array}{l}\text { Un total de } 188 \text { magrebíes y sub- } \\
\text { saharianos participantes en el } \\
\text { programa Integra. }\end{array}$ & $\begin{array}{l}\text { Tamaño: } 2.12 \text { familiares y } 4.49 \\
\text { compatriotas y españoles }\end{array}$ \\
\hline Maya Jariego (2003) & $\begin{array}{l}\text { Marroquíes }(n=81) \text {, filipinos }(69), \text { y } \\
\text { senegaleses }(23) \text { residentes en } \\
\text { Marbella. }\end{array}$ & $\begin{array}{l}\text { Tamaño: } 8.03 \text {, con más de dos } \\
\text { tercios de compatriotas. }\end{array}$ \\
\hline $\begin{array}{l}\text { Maya Jariego, Martínez } \\
\text { \& García (1999) }\end{array}$ & $\begin{array}{l}\text { Mujeres inmigrantes peruanas ( } n= \\
\text { 55) y marroquíes }(50) \text {. }\end{array}$ & $\begin{array}{l}\text { Tamaño: } 7.54 \text { en las peruanas y } \\
4.82 \text { en las marroquíes. En más de } \\
\text { un } 95 \text { por ciento compuestas por } \\
\text { compatriotas. }\end{array}$ \\
\hline $\begin{array}{l}\text { Martínez, García, Maya } \\
\text { Jariego, Rodríguez \& } \\
\text { Checa (1996) }\end{array}$ & $\begin{array}{l}\text { Muestra representativa de } 600 \\
\text { inmigrantes africanos residentes en } \\
\text { Andalucía. }\end{array}$ & $\begin{array}{l}\text { Tamaño: } 3.75 \text {, con dos tercios de } \\
\text { compatriotas. }\end{array}$ \\
\hline
\end{tabular}

Tabla 1. Las redes de apoyo de los inmigrantes recientes.

La adaptación psicológica del inmigrante puede describirse como un proceso de reconstrucción de su red activa de apoyo. Generalmente se produce un crecimiento paulatino que coincide con una distribución más equilibrada de las funciones de apoyo entre los proveedores disponibles. Dos de los fenómenos que contribuyen decisivamente a dicho desarrollo son el reagrupamiento de la familia y la integración en la comunidad local. Ambos repercuten en el tamaño y en la distribución de los lazos múltiples en la red personal del inmigrante. En los próximos apartados intentaremos explicar estos cambios desde distintos puntos de vista. En primer lugar nos centramos en el nivel colectivo de las cadenas migratorias.

\section{Las cadenas migratorias}

Los cambios en las redes personales que acabamos de describir forman parte de un proceso más amplio, en el que la reubicación geográfica atañe a poblaciones de individuos. Podemos decir, metafóricamente, que las redes sociales "emigran" de un lugar a otro. Se trata de un fenómeno que tiene consecuencias importantes. Por ejemplo, son varias las formas en las que las cadenas pueden condicionar la evolución de las redes personales: 
REDES- Revista hispana para el análisis de redes sociales

Vol.17,\#13, Diciembre 2009

http://revista-redes.rediris.es

Los inmigrantes pertenecen a comunidades relacionales muy dinámicas, en pleno proceso de cambio. No en vano están formadas por un conjunto de individuos que están reconstruyendo su red personal. Por eso cabe esperar una gran labilidad relacional dentro del colectivo. Podemos sostener la hipótesis de que la tasa de cambio en las relacionales personales de los inmigrantes es mayor que la que se da en las comunidades de origen y de destino. Se trataría, por tanto, de un sistema de relaciones más inestable (especialmente en las fases iniciales de re-asentamiento).

El tamaño y la organización de la comunidad expatriada configuran la estructura de oportunidades para el establecimiento de nuevos contactos. Por ejemplo, no es comparable la situación de un pequeño grupo de pioneros, que trata de abrirse camino, con la de los inmigrantes de cadenas maduras, que se incorporan a un colectivo ya asentado. Es de suponer que el número de compatriotas presentes en el lugar de destino repercute en el tamaño y la composición de las redes personales de los recién llegados.

El grado de reagrupamiento familiar puede condicionar la distribución de las funciones de apoyo. La emigración suele suponer -ya sea de forma completa o parcialmente- la separación respecto al círculo más cercano de familiares y amigos. Un grupo que generalmente tiene un papel central como proveedores de apoyo social. Es frecuente que el individuo deposite gran parte de sus expectativas de ayuda en los recursos que tiene disponibles, en sustitución de la familia. Pero a medida que se produce el reagrupamiento dichas funciones pueden retornar a los parientes más cercanos.

Como vemos, desde el punto de vista de las cadenas migratorias, la emigración puede ser entendida como el proceso de reubicación e incorporación de la red social de la minoría inmigrante en una comunidad receptora más amplia y estructurada. Eso conlleva cambios en las relaciones dentro y fuera del colectivo que se desplaza, que son centrales a la hora de entender la evolución del reasentamiento individual.

Recurrimos a las cadenas migratorias para comprender la decisión de emigrar, la difusión de la emigración en la estructura social, la adaptación psicológica, la inserción en la minoría de compatriotas y en la comunidad receptora más amplia, y las pautas de segregación social. El devenir de los colectivos inmigrantes corresponde en cierto grado a la evolución de la cadena migratoria. Un buen ejemplo lo proporciona el colectivo de inmigrantes indios sikhs en Gran Bretaña. Pese a tratarse de un grupo muy estricto en su comportamiento religioso, que tiene entre sus prácticas no beber alcohol, en las primeras fases de asentamiento se observaron muchos casos de alcoholismo. Sin embargo, el crecimiento de la 
REDES- Revista hispana para el análisis de redes sociales

Vol.17,\#13, Diciembre 2009

http://revista-redes.rediris.es

comunidad con nuevos compatriotas fue recuperando las pautas de control social, reduciendo significativamente la incidencia de nuevos casos.

También podemos ilustrarlo con datos propios. En la Figura 2 tenemos un ejemplo de reagrupamiento familiar en cadena. Corresponde a un estudio que llevamos a cabo con inmigrantes indios en Argentina ${ }^{7}$. Dhan Singh es el padre de uno de nuestros informantes clave de segunda generación asentados en Salta. Dhan llegó a la Argentina en barco en 1937: bajó clandestinamente en el puerto de Buenos Aires y se trasladó a Rosario de la Frontera, en la provincia de Salta. Es el precursor de seis desplazamientos posteriores. Por eso Tara, su primo, lo describe como una especie de "patriarca", con gran influencia sobre el resto de familiares. Dhan facilita sucesivamente la emigración de un hermano (Gurdial), un primo (Ardit) y un amigo (Jiwa). A su vez, el primo Ardit trae a un hermano (Tara), y éste a su primo (Sukhdev). Finalmente, después de que la familia arregle el casamiento, Sukhdev viaja a la India para casarse y llevar a su esposa (Baljeet) hasta Argentina. Este proceso de reagrupamiento se extiende, desde su inicio hasta la llegada de Baljeet, a lo largo de 37 años.

Es fácil deducir, por ejemplo, las diferencias en el proceso de adaptación de Dhan y Sukhdev. El primero es el pionero de esta cadena familiar, que llega a la Argentina cuando apenas hay otros compatriotas asentados. Se ve entonces en la tesitura de crearse un entorno de acogida, y tiene posiblemente muchas oportunidades para la asimilación social con argentinos. Por el contrario, Sukhdev cuenta con un grupo familiar relativamente amplio que lo recibe. Además, dispone de las relaciones indirectas que sus familiares han ido constituyendo, facilitando el proceso de integración social. Es decir, se incorpora a un grupo de familiares y compatriotas, que a su vez está rodeado por el tejido social que los mismos han ido trenzando a lo largo de décadas.

\footnotetext{
${ }^{7}$ Realizado con Lía de la Vega, Universidad del Salvador (Buenos Aires, Argentina).
} 
REDES- Revista hispana para el análisis de redes sociales

Vol.17,\#13, Diciembre 2009

http://revista-redes.rediris.es

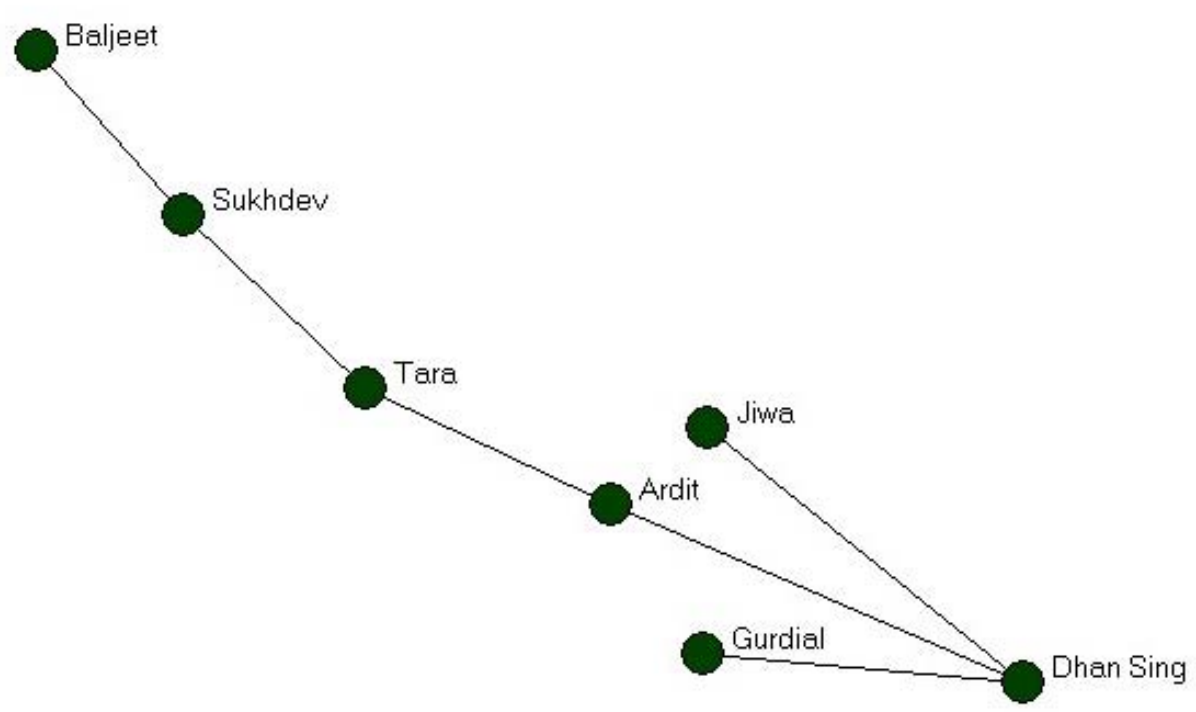

Figura 2. Cadena de reagrupación familiar de un grupo de inmigrantes indios en Argentina.

Esta misma dinámica la resumía de modo muy convincente un entrevistado haitiano, con el que hablábamos sobre sus relaciones personales en Sevilla: "no basta con que yo me vuelva a hacer una red con amigos y con conocidos. La diferencia está en que ya no tengo a mano las redes que tejieron mis abuelos. Eso es ser inmigrante". Efectivamente, la reubicación geográfica no sólo transforma el sistema de apoyo más inmediato sino que modifica el encaje del individuo en la estructura social de referencia. La persona suele ser consciente de los cambios que experimenta su entorno más íntimo. Por lo general está activamente implicada en la recuperación y el mantenimiento de contactos, y en el desarrollo de otros nuevos. Sin embargo, no está al tanto de los cambios que, a través de las cadenas de emigración, experimentan las estructuras sociales de origen y de destino. En otras palabras, lo que queremos decir es que la estructura social tiene efectos inconscientes que la literatura psicológica de apoyo social no toma en consideración, pero que proporcionan el contexto para comprender la dinámica de las redes personales.

\section{Los intercambios de apoyo}

A través de las redes fluyen recursos instrumentales y expresivos. Los inmigrantes obtienen de sus relaciones personales compañía, consejo, dinero y soporte afectivo, entre otros muchos tipos de ayuda. Cada individuo es proveedor y receptor de apoyo al mismo tiempo, de forma que cabe interpretar el apoyo social como una dinámica de intercambio entre actores sociales. 
REDES- Revista hispana para el análisis de redes sociales

Vol.17,\#13, Diciembre 2009

http://revista-redes.rediris.es

En las transacciones de apoyo entran en juego la disponibilidad de recursos que intercambiar, la adecuación de los recursos a las necesidades existentes, y las dinámicas de reciprocidad y endogamia en las relaciones:

Los inmigrantes recientes suelen asociarse en pequeños grupos de compatriotas. Es frecuente que todos se encuentren en una misma situación de necesidad. A veces carecen de recursos para compartir, especialmente cuando se trata de aspectos materiales e instrumentales. Sin embargo, estas agrupaciones son de gran valor en el proceso de adaptación. Garantizan un mínimo de ayuda cuando se ha reducido de modo considerable el apoyo disponible. También permiten compartir las experiencias y el estrés de aculturación con otros que pasan por una situación similar.

La naturaleza de los intercambios depende de la modalidad de ayuda. El apoyo instrumental se basa en la posesión de determinados recursos tangibles, mientras que en el caso del apoyo psicológico puede ser suficiente, con frecuencia, mostrarse disponible. Además, la compañía y la expresión de sentimientos personales pueden estar implícitas en otras formas de apoyo. No obstante, tanto en un caso como en otro, suele haber una expectativa de reciprocidad en la relación, aunque esta no sea específica al tipo de recurso compartido.

Por otro lado, los intercambios se ven delimitados por la homofilia en las relaciones. Hay cierta tendencia a relacionarse con personas con las que se comparten características comunes. Por ejemplo, se forman agrupaciones en función de la edad, el género, el grupo étnico, el tipo de trabajo, etcétera. Pero estos asociados suelen ser similares también en el tipo y la cantidad de recursos que poseen, de modo que refuerzan el rol social preexistente, y dificultan la movilidad social.

Veamos un ejemplo para ilustrar las dinámicas del intercambio de ayuda. En este caso se trata de un estudio comparativo, con inmigrantes paraguayos y bolivianos en Argentina, y marroquíes en España ${ }^{8}$. En la Figura 3 se representan los niveles de apoyo otorgado y recibido durante el último mes en ocho tipos de ayuda diferentes.

En primer lugar, comprobamos que el intercambio de apoyo psicológico es más frecuente que el instrumental, y muestra en promedio una mayor correspondencia entre lo que se aporta y lo que se recibe. Dar dinero o alojamiento son los comportamientos menos frecuentes. Por el contrario, los más habituales son compartir las preocupaciones y mostrarse disponible para ayudar cuando sea necesario.

${ }^{8}$ Realizado con Graciela Tonón, Universidad de Lomas de Zamora y Universidad Nacional de La Matanza (Buenos Aires, Argentina). 
REDES- Revista hispana para el análisis de redes sociales

Vol.17,\#13, Diciembre 2009

http://revista-redes.rediris.es

Tomando en su conjunto los resultados, parece que los intercambios de apoyo guardan cierta relación con el nivel de reagrupamiento familiar. Tanto el apoyo otorgado como la tasa de intercambio son mayores en aquellos que contaban con otros familiares ya emigrantes que en los que hicieron de pioneros o simplemente no contaban con otros emigrantes en la familia.

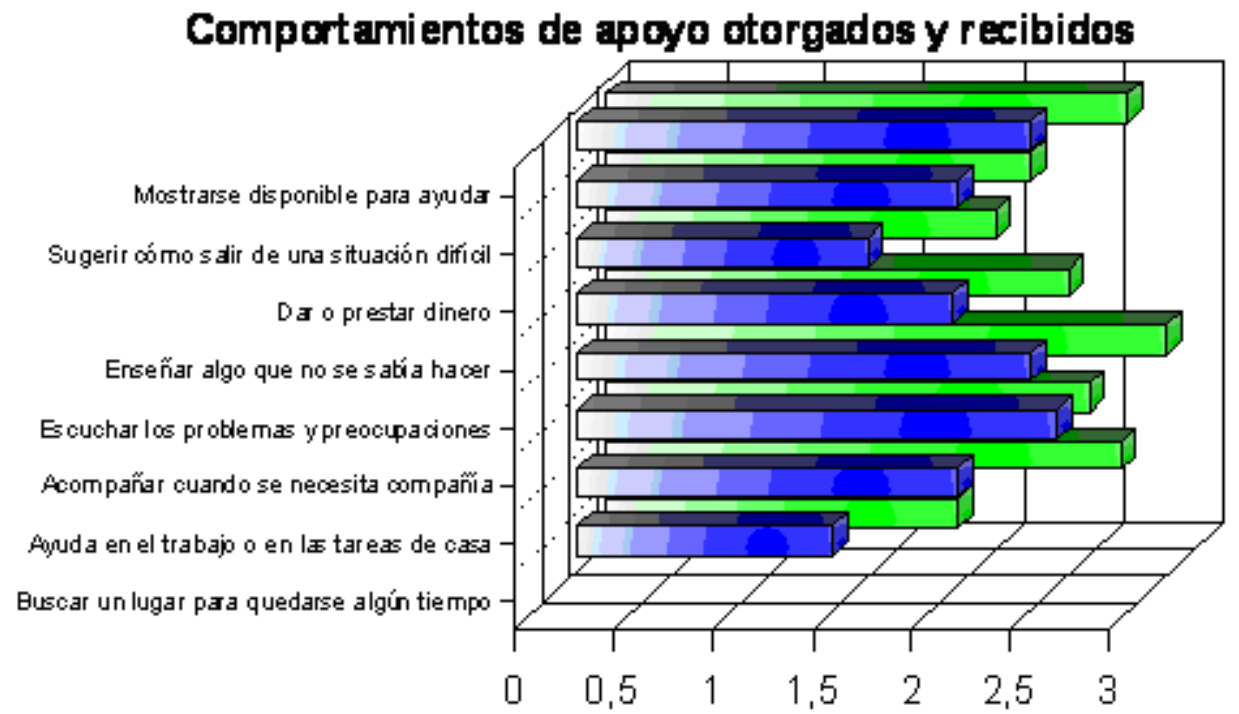

Apoyo otorgado

Apoyo recibido

Figura 3. Intercambios de apoyo en paraguayos y bolivianos en Argentina y marroquíes en España Esta descripción general es válida para los tres grupos estudiados. Sin embargo, también se observan algunas diferencias entre colectivos. Por ejemplo, los marroquíes afirman recibir significativamente más ayuda económica y más atención a sus problemas personales que los otros dos grupos. Este colectivo también difiere en los patrones de reciprocidad, como se observa en la Figura 4. La ratio refleja la relación entre el nivel de apoyo otorgado y el nivel de apoyo recibido ${ }^{9}$. En todos los comportamientos es mayor la ayuda que se da que la que se recibe, y la magnitud de la diferencia entre ambas es equiparable ${ }^{10}$. Donde menos reciprocidad se observa es en las tareas domésticas, el préstamo de dinero y la escucha activa de problemas.

\footnotetext{
${ }^{9}$ Ratio = apoyo otorgado / apoyo recibido. La ratio es negativa cuando, en conjunto, se da más de lo que se recibe. En este caso estamos analizando la reciprocidad por tipos de apoyo, aunque probablemente se trata de una distinción que no hacen los entrevistados. La percepción de los intercambios es generalmente más global que analítica.

${ }^{10}$ Excepto en el caso de la compañía que es, por definición, un comportamiento recíproco.
} 
REDES- Revista hispana para el análisis de redes sociales

Vol.17,\#13, Diciembre 2009

http://revista-redes.rediris.es

El grupo de marroquíes es el que cuenta con peor ratio de comportamientos de apoyo. A pesar de proporcionar niveles equiparables a los otros dos grupos tiene un índice más alto de apoyo recibido. Esta diferencia se confirma tanto en la recepción de apoyo instrumental como en la recepción de apoyo psicológico. En cualquier caso, la ratio resulta particularmente negativa en lo que hace referencia a la ayuda instrumental. Los marroquíes tienen ratios negativas en los dos tipos de apoyo, y los paraguayos sólo en relación al apoyo instrumental. Por su parte, los bolivianos tienen ratios positivas en ambas categorías.

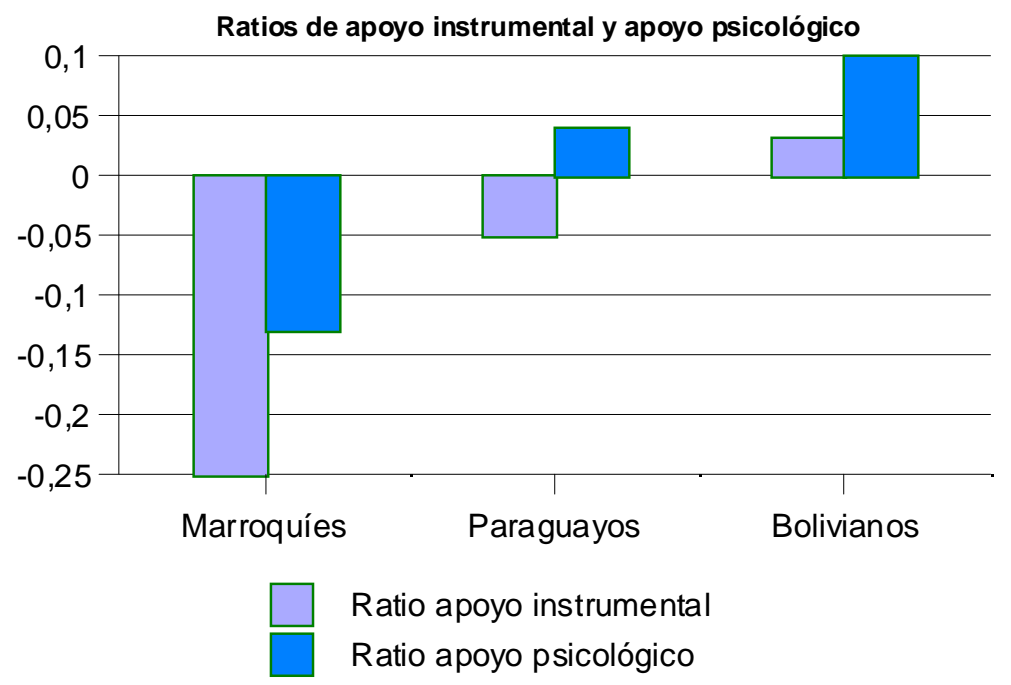

Figura 4. Reciprocidad de los intercambios de ayuda en tres colectivos de inmigrantes.

Con este ejemplo hemos mostrado que la modalidad de los recursos, expresivos e instrumentales, sirve para caracterizar el tipo de relación que se desarrolla. Los vínculos varían de acuerdo con la cantidad y la modalidad de los recursos que se intercambian. Pese a ello, los patrones de intercambio específicos están en gran medida determinados por el contexto de la relación. La estructura de oportunidades y la disponibilidad de recursos limitan las posibilidades de dar y recibir ayuda. De hecho, este es uno de los fenómenos que con más claridad se observa entre los inmigrantes recientes.

\section{La multiplicidad de los proveedores de ayuda}

La multiplicidad se refiere a la cantidad de tipos de ayuda que proporciona cada proveedor. Por ejemplo, hay personas a las que sólo recurrimos cuando queremos obtener consejo. Sin embargo, otras actúan como confidentes, prestan dinero y 
REDES- Revista hispana para el análisis de redes sociales

Vol.17,\#13, Diciembre 2009

http: // revista-redes.rediris.es

proporcionan ayuda instrumental al mismo tiempo. Ambos casos muestran diferentes niveles de intensidad, frecuencia o "fortaleza" del vínculo, y revelan la existencia de diferentes tipos de relación.

La estructura de la red personal suele contar con un pequeño núcleo de familiares y amigos íntimos. Se trata de relaciones sinérgicas, que satisfacen varios tipos de necesidades, y que constituyen un grupo relativamente estable a lo largo del tiempo. Son los proveedores con un nivel más elevado de multiplicidad. En torno a ellos se da un conjunto más amplio de vínculos especializados, con los que la relación es menos fuerte, y que cambian con más facilidad.

¿Es válida esta descripción cuando nos referimos a la población inmigrante? ¿Afecta el desplazamiento a la distribución de la multiplicidad en la red personal? En el estudio de los inmigrantes indios en Argentina, que ya hemos mencionado, elaboramos una tipología de los vínculos que proporcionan ayuda. En primer lugar, aplicamos una entrevista de apoyo social que examina 6 tipos de ayuda diferentes: apoyo confidente, ayuda material, consejo, reforzamiento social, ayuda instrumental y compañía ${ }^{11}$. A continuación analizamos de modo sistemático las múltiples combinaciones de tipos de apoyo en el conjunto de proveedores. En concreto, examinamos la combinatoria de los 6 tipos en un total de 2.226 proveedores de apoyo mencionados por los entrevistados.

Esto significa que existen hasta 64 combinaciones posibles, si tomamos en consideración la presencia o ausencia de cada una de dichas categorías. Por ejemplo, un vínculo proporciona consejo y reforzamiento social; otro proporciona consejo, reforzamiento social y compañía, etcétera. A priori podríamos encontrar hasta 64 tipos de vínculos diferentes. Sin embargo, fueron necesarios muchos menos para tener una visión de conjunto. Como observamos en la Tabla 2, con sólo 11 tipos de vínculos tenemos prácticamente tres cuartas partes del total de 2.226 proveedores analizados:

Más de la mitad proporcionan sólo un tipo de ayuda puntual (52.2\%), destacando la compañía como el recurso más extendido.

El 12.71 por ciento alcanza el carácter de vínculo sinérgico, estando disponible prácticamente para cualquier tipo de demanda de apoyo.

Finalmente, cabe destacar un pequeño grupo de socios o compañeros $(9.07 \%)$, que proporcionan diferentes combinaciones de apoyo afectivo, reforzamiento social y compañía.

\footnotetext{
${ }^{11}$ Se trata de la Arizona Social Support Interview Schedule, de Manuel Barrera.
} 
REDES- Revista hispana para el análisis de redes sociales

Vol.17,\#13, Diciembre 2009

http://revista-redes.rediris.es

Es decir, hay tres niveles bastante definidos de multiplicidad en la relación, que corresponden a otros tantos tipos de relación, según la modalidad de ayuda que prestan: contactos especializados, que proporcionan un tipo de apoyo puntual; compañeros, con los que se comparte apoyo afectivo e informativo; y vínculos sinérgicos, que corresponden a las relaciones más íntimas y polivalentes.

Haciendo abstracción de otras consideraciones, en la red de apoyo hipotética de un inmigrante indio en la Argentina, 7 de cada 10 vínculos proporcionan apoyo especializado. La red cuenta, además, con un pequeño núcleo de vínculos sinérgicos, que ve reforzadas sus funciones por un segmento, también reducido, de compañeros. En este caso nos referimos a un colectivo con miembros de primera y segunda generación, y con un elevado tiempo de estancia en promedio, en el que la descripción puede ser bastante parecida a la que encontraríamos en la población general. Probablemente en los inmigrantes más recientes se puede observar, junto a la reducción del tamaño de la red de apoyo, una mayor concentración de funciones en los vínculos disponibles.

La multiplicidad nos permite pensar en la evolución de las relaciones interpersonales, así como en la distribución de las funciones de apoyo, tanto en el nivel individual como en el colectivo.

Podemos suponer que las relaciones ganan en multiplicidad a lo largo del tiempo. Es decir, un proveedor de ayuda es un contacto especializado antes de convertirse en un compañero con el que compartimos compañía y consejos. Con el tiempo, el compañero puede convertirse, además, en un amigo polivalente, que proporciona un soporte sinérgico. Desde este punto de vista, las relaciones personales se desarrollan en pasos sucesivos de mayor profundidad y amplitud. La vida de las relaciones - pese a que hay avances, frenos y retrocesos- tiene un camino trazado, que corresponde al intercambio escalonado de nuevas modalidades de recursos, pasando de un contexto de relación especializado a compartir espacios sociales diversos. Supongamos que un compañero de trabajo se convierte en amigo. En la transición de un tipo de relación a otra los contenidos de los intercambios ganan en diversidad. Se pasa de las conversaciones sobre temas laborales a los consejos personales, o a la ayuda en caso de mudanza. Además, la relación se extiende a través de diferentes contextos: sale del lugar de trabajo y puede recrearse en la casa de ambos o en un campo de fútbol. 


\begin{tabular}{|c|c|c|c|c|c|c|c|c|c|}
\hline & $\mathbf{A}$ & $\mathbf{B}$ & \begin{tabular}{l|l}
$\mathbf{C}$ & \\
\end{tabular} & D & \begin{tabular}{l|l}
$\mathbf{E}$ & $\mathbf{I}$
\end{tabular} & $\mathbf{F}$ & Frecuencias & Porcentaje & \begin{tabular}{|l} 
Porcentaje \\
acumulado
\end{tabular} \\
\hline Proveedor de compañía & & & & & & $x$ & 659 & 29.60 & 29.60 \\
\hline Vínculo sinérgico 1 & $\mathrm{x}$ & $\mathrm{X}$ & $\mathrm{x}$ & $\mathrm{X}$ & $\mathrm{x} \mid \mathrm{z}$ & $x$ & 220 & 9.88 & 39.48 \\
\hline $\begin{array}{r}\text { Proveedor de ayuda } \\
\text { física }\end{array}$ & & & & & $x$ & & 140 & 6.29 & 45.77 \\
\hline $\begin{array}{r}\text { Proveedor de ayuda } \\
\text { material }\end{array}$ & & $\mathrm{X}$ & & & & & 132 & 5.93 & 51.70 \\
\hline $\begin{array}{r}\text { Proveedor de feedback } \\
\text { positivo }\end{array}$ & & & & $X$ & & & 126 & 5.66 & 57.36 \\
\hline Compañero 1 & & & & $\mathrm{X}$ & & $x$ & 100 & 4.49 & 61.85 \\
\hline Vínculo sinérgico 2 & $\mathrm{X}$ & $\mathrm{X}$ & $x$ & $\mathrm{X}$ & & $x$ & 63 & 2.83 & 64.68 \\
\hline Compañero 2 & $\mathrm{X}$ & & & $\mathrm{X}$ & & $\mathrm{X}$ & 61 & 2.74 & 67.42 \\
\hline Proveedor de consejo & & & $\mathrm{X}$ & & & & 54 & 2.43 & 69.85 \\
\hline $\begin{array}{r}\text { Proveedor de apoyo } \\
\text { confidente }\end{array}$ & $x$ & & & & & & 51 & 2.29 & 72.14 \\
\hline Compañero 3 & $\mathrm{X}$ & & & & & $x$ & 41 & 1.84 & 73.98 \\
\hline
\end{tabular}

Tabla 2. Las 11 configuraciones de multiplicidad más frecuentes

Tipos de ayuda: A, apoyo afectivo o expresión de sentimientos personales; B, ayuda material o tangible; C, consejo o información; D, feedback positivo o reforzamiento social; E, ayuda física o instrumental; y F, compañía o participación social.

Sin embargo, todos contamos con un espacio limitado de relaciones, referido a unas coordenadas espacio-temporales definidas. Disponemos de un número reducido de vínculos polivalentes, que corresponde a una lógica de distribución de las funciones de apoyo. Cuando una relación gana en profundidad es posible que otra esté pasando a un segundo plano. Podemos formularlo como una hipótesis de competencia entre el conjunto de relaciones múltiples activas. Por ejemplo, cuando un joven empieza a estudiar en la Universidad sus relaciones de amistad cambian y aparecen nuevas relaciones en su espacio más íntimo y cercano. Algunos de los amigos de la infancia pueden quedar latentes, fuera del núcleo de intercambios activos. Aunque la relación con el amigo de la infancia pueda recuperarse en cualquier momento y hacerse activa en circunstancias de crisis, ya no forma parte del grupo privilegiado de proveedores múltiples de apoyo activos. Por eso la multiplicidad es una buena forma de evaluar en qué parte de la red personal se están produciendo los intercambios de apoyo en un momento determinado de la vida del individuo.

Finalmente, también podemos referirnos a la distribución colectiva de los lazos múltiples. I gual que hemos hablado de la distribución de las relaciones de apoyo en la red personal, podemos hablar de la distribución de la multiplicidad en un plano colectivo. Podemos interpretar las relaciones múltiples como parte de un mercado colectivo de apoyo social. Pasar tiempo con unos individuos significa no pasarlo con otros. A no ser que pensemos en términos de agrupaciones de amigos y conocidos. 
REDES- Revista hispana para el análisis de redes sociales

Vol.17,\#13, Diciembre 2009

http://revista-redes.rediris.es

Pero, una vez más, pasar tiempo con unas agrupaciones significa no pasarlo con otras. Los grupos de inmigrantes pioneros pueden formar grupos cohesivos como consecuencia de la escasez de recursos y la restricción de las oportunidades. Sin embargo, a medida que crece la comunidad de compatriotas el desarrollo de relaciones múltiples introduce un componente disgregador, que se traduce en la formación de agrupaciones.

Para los inmigrantes el desplazamiento significa que muchas de sus relaciones cambian de estatus o quedan latentes. En el esfuerzo de reasentamiento las funciones de apoyo se concentran en los (a veces escasos) recursos disponibles. Como es lógico, el desarrollo de nuevas relaciones polivalentes requiere tiempo. No obstante, en la medida en que se produce el reagrupamiento de la familia tiene lugar una nueva reorganización de las funciones de apoyo, alterando qué vínculos son múltiples y cuáles no.

\section{Los tipos de redes personales de los inmigrantes}

Como hemos comprobado a lo largo de estas páginas, la inmigración es una forma de transición ecológica. Con la reubicación geográfica, concurren cambios en el tamaño, la composición y la estructura del sistema de relaciones personales de los inmigrantes.

La dinámica de las redes personales es un reflejo de la adaptación psicológica en el nuevo contexto. Por eso el examen sistemático del apoyo social es una herramienta útil para describir la aculturación y la acomodación del individuo. En concreto, la elaboración de una tipología de redes es una estrategia eficiente para clasificar a los inmigrantes en función de su marcha en el lugar de destino. Permite identificar las constelaciones más frecuentes de apoyo y, a través de ellas, las condiciones de adaptación del individuo.

Ese fue el enfoque que seguimos con africanos y latinoamericanos en España. Con cinco muestras diferentes, aplicamos sendos análisis de conglomerados de sus redes personales. A continuación las integramos en una única clasificación a través del cluster jerárquico ${ }^{12}$. En la Tabla 3 se resume la tipología resultante.

Las redes de apoyo varían en tamaño y composición, a través de un continuo que las hace más amplias y más heterogéneas. Las redes crecen desde el endo-grupo hacia el exo-grupo, desde la familia a los amigos, y desde los compatriotas hacia

\footnotetext{
12 Se trata de una tipología de redes de apoyo de inmigrantes con menos de 10 años de residencia en España (véase, para una descripción detalla del procedimiento, Maya Jariego, 2003c). Se basa en cinco estudios con latino-americanos y africanos. Se hicieron clasificaciones utilizando como variables criterio (1) el tamaño, (2) la presencia de familiares y (3) la presencia de españoles. Finalmente, se integraron las 17 categorías de las clasificaciones previas, utilizando los centroides en las tres variables antes mencionadas.
} 
REDES- Revista hispana para el análisis de redes sociales

Vol.17,\#13, Diciembre 2009

http://revista-redes.rediris.es

los miembros de la sociedad receptora. El reagrupamiento y la incorporación de españoles son las dos estrategias básicas de desarrollo de la red.

Las configuraciones más frecuentes están compuestas de familiares y compatriotas, con un tamaño comparativamente pequeño o medio. Entre las mujeres, especialmente cuando están divorciadas o viudas, se dan con más frecuencia las estructuras de apoyo insuficientes, que coinciden con una prevalencia de la depresión significativamente más alta. Entre los hombres, jóvenes, solteros y latinoamericanos se dan niveles más elevados de asimilación social, con redes más amplias y más contacto con españoles.

\begin{tabular}{lcc}
\hline Tipo de red personal & Tamaño & Perfil \\
\hline Red mínima & & $\begin{array}{c}\text { Mujeres. Marroquíes. Divorciadas } \\
\text { y viudas. Altas puntuaciones en } \\
\text { depresión. }\end{array}$ \\
\hline
\end{tabular}

$\begin{array}{lcc}\begin{array}{l}\text { Red pequeña con mayoría de amigos } \\ \text { compatriotas }\end{array} & \begin{array}{c}\text { 4-6 Proveedores. En su } \\ \text { mayoría compañeros } \\ \text { inmigrantes }\end{array} & \begin{array}{c}\text { Tipo con más prevalencia entre } \\ \text { los inmigrantes recientes. }\end{array}\end{array}$

Red de tamaño medio con predominio de no familiares y españoles

Red amplia de reagrupamiento familiar
10-15 Proveedores
Estable en términos socioeconómicos. Intención de permanencia en España.
Redes amplias de reagrupamiento integradas en la comunidad local
12-15 Proveedores

Hombres. Solteros. Jóvenes.

Tabla 3. Hacia una tipología general de las redes personales de los inmigrantes

\section{Lazos que traspasan fronteras}

La emigración internacional pone en contacto a poblaciones de países diferentes. El inmigrante es un lazo entre estructuras sociales separadas, de modo que áreas geográficas dispersas se acercan con el intercambio de flujos de población. La inmigración es, por tanto, en sí misma un cambio en los patrones de relación, que hace el mundo más pequeño en la medida en que media entre comunidades relacionales diferentes. Desde un punto de vista sistémico, países y poblaciones se 
REDES- Revista hispana para el análisis de redes sociales

Vol.17,\#13, Diciembre 2009

http: // revista-redes.rediris.es

relacionan a través del desplazamiento de personas, las visitas, los intercambios de bienes y servicios, las remesas económicas, los flujos de comunicación, etcétera. El mismo enfoque podemos aplicarlo cuando nos referimos a las redes personales.

La búsqueda de apoyo puede cruzar las fronteras nacionales. Por ejemplo, los sistemas de apoyo familiar de los caribeños inmigrantes en Estados Unidos son de gran profundidad, amplitud y frecuencia, a pesar de la dispersión internacional. En algunos casos se llega a hablar de la "internacionalización del parentesco". Con ese término se hace referencia a la dispersión geográfica de los miembros del núcleo familiar. En particular cuando se consigue el mantenimiento del mismo a través de la comunicación constante, los viajes y los intercambios de bienes y servicios.

Sin embargo, en nuestra investigación hemos observado que los individuos tienen una capacidad limitada para el mantenimiento de vínculos activos transnacionales. Especialmente en las fases iniciales de reasentamiento, la red personal experimenta cambios muy significativos en su funcionamiento psicológico. También los vínculos afincados en el país de origen con los que se mantiene contacto cambian en el papel que desempeñan en la red de apoyo. Concretamente se ve afectada la frecuencia de contacto y la modalidad de ayuda que proporcionan, e incluso ocasionalmente pueden adquirir el carácter de lazos latentes. Con ello no queremos interpretar en términos de déficit o carencia las transformaciones que experimenta el inmigrante, sino reflejar los cambios que conlleva la transición entre espacios socio-geográficos diferentes que, para el caso que nos ocupa, es de largo alcance.

En la inmigración internacional se producen cambios en la integración social, en la estructura de la red social y en las funciones de apoyo que se derivan de las mismas. El individuo se traslada a una comunidad donde tiene un encaje estructural más débil, y mayor movilidad relacional. Ese cambio coincide con una menor disponibilidad de ayuda y una mayor concentración de las funciones de apoyo.

El proceso de adaptación psicológica se refleja en los cambios de la red personal. A lo largo del tiempo tiene lugar la reconstrucción del tamaño, la estructura y la dinámica funcional. Las redes de apoyo crecen paulatinamente a través de la asociación con compatriotas, el reagrupamiento de la familia y los contactos con españoles. La aculturación modifica la composición de la red personal, que gana en heterogeneidad, y afecta también al grado de cohesión estructural, puesto que aparecen con más frecuencia agrupaciones definidas de actores. Con todos estos cambios se reorganiza la distribución de las funciones de apoyo, que recupera un mayor equilibro entre los proveedores implicados. 
REDES- Revista hispana para el análisis de redes sociales

Vol.17,\#13, Diciembre 2009

http://revista-redes.rediris.es

Pero cuando se emigra a otro país las relaciones que atendían las necesidades del individuo antes del desplazamiento no han desaparecido. Su naturaleza se ha transformado, y de algún modo ha de reflejarse en la estructura de la red personal. La vida no ha pasado en vano.

\section{Bibliografía}

Araya, R. \& Maya Jariego, I. (2005). Los puentes interlocales: las redes personales de los universitarios alcalareños en Sevilla. En Porras, J. I. \& Espinoza, V. (Eds.). Redes. Enfoques y aplicaciones del análisis de redes sociales, pp. 183-213. Universidad Santiago de Chile y Universidad Bolivariana. Santiago de Chile, Chile.

Aroian, K.J. (1992): Sources of Social Support and Conflict for Polish Immigrants. Qualitative Health Research, vol.2, no2, May, 178-207.

Boyd, M. (1989). Family and Personal Networks in International Migration: Recent Developments And New Agendas. International Migration Review, 23, 3, 638-670.

Delgado,M. y Humm-Delgado,D. (1982): Natural support systems: source of strength in Hispanic communities. Social Work, Jan, 83-89.

Die,A.H., Seelbach,W.C. (1988): Problems, sources of assistance, and knowledge of services among elderly vietnamese immigrants. The Gerontological Society of America, Vol.28, no 4, 448-452.

Ferrand, A. (2002). "Las comunidades locales como estructuras meso", Redes. Revista Hispana para el Análisis de Redes Sociales, 3 (4). Consulta [14-06-2006] en <http://revista-redes.rediris.es>.

García, M., Martínez, M. F., Balcázar, F. E., Suárez-Balcázar, Y., Albar, M. J., Domínguez, M. E. \& Santolaya, F. J. (2005). Psychosocial empowerment and social support factors associated with the employment status of immigrant welfare recipients. Journal of Community Psychology, 33 (6), 673-690.

Golding,M.J. y Baezconde-Garbanati,L.A. (1990): Ethnicity, Culture and Social Resources. American J ournal of Community Psychology, vol.18, no3.

Kutsche,P. (1983): Household and family in hispanic northern New Mexico. Journal of Comparative Family Studies, vol.14, nำ, 151-165.

Ho,C.G. (1993): The internationalization of kinship and the feminization of Caribbean migration: The case of Afro-Trinidadian Immigrants in Los Angeles. Human Organization, Spr. Vol.52 (1) 32-40. 
REDES- Revista hispana para el análisis de redes sociales

Vol.17,\#13, Diciembre 2009

http://revista-redes.rediris.es

Leslie,L.A. (1992): The role of informal support networks in the adjustment of Central American immigrant families. Journal of Community Psychology, Jul. Vol. 20 (3), 243-256.

Litwin,H. (1995): The social networks of elderly immigrants: An analytic typology. Journal of Aging Studies, Sum Vol 9(2) 155-174.

Lynam,M.J. (1985): Support networks developed by immigrant women. Social Science and Medicine, Vol. 21 (3), 327-333.

Martínez, M. F., García, M., y Maya Jariego, I. (2002). Social support and locus of control as predictors of psychological well-being in Moroccan and Peruvian immigrant women in Spain. International Journal of Intercultural Relations, 26 (3), 287-310.

Martínez, M. F., García, M., y Maya Jariego, I. (2001). Una tipología analítica de las redes de apoyo social en inmigrantes africanos en Andalucía. Revista Española de Investigaciones Sociológicas, 95, 99-125.

Martínez, M. F., García, M., y Maya Jariego, I. (2001b). El efecto amortiguador del apoyo social sobre la depresión en un colectivo de inmigrantes. Psicothema, 13 (4), 605-610.

Martínez, M. F., García, M., y Maya Jariego, I. (2001c). El rol del apoyo social y las actitudes hacia el empleo en el emplazamiento laboral de inmigrantes. Anuario de Psicología, 32 (3), 51-65.

Martínez, M. F., García, M., y Maya Jariego, I. (2000). Inserción socio-laboral de inmigrantes en Andalucía: el programa Horizon. Junta de Andalucía. Consejería de Asuntos Sociales.

Martínez, M.F., García, M., Maya Jariego, I., Rodríguez, S. y Checa, F. (1996). La integración social de los inmigrantes africanos en Andalucía. Necesidades y Recursos. Junta de Andalucía. Consejería de Trabajo e Industria.

Massey, D.S., Goldring, L. y Durand, J. (1994). Continuities in Transnational Migration: An Analysis of Nineteen Mexican Communities. American Journal of Sociology, 99, 1492-1533.

Maya Jariego, I. (2006). Communautés transnacionales et communautés locales: une étude des réseaux personnels d'espagnols et d'étrangers en Andalousie (Espagne). MECIT, Centre lillois d'études et de recherches sociologiques et économiques, Lillé (Francia), 15 de mayo de 2006. 
REDES- Revista hispana para el análisis de redes sociales

Vol.17,\#13, Diciembre 2009

http://revista-redes.rediris.es

Maya Jariego, I. (2004). La formación de comunidades de inmigrantes: desplazamiento en cadena y contexto de recepción. Araucaria. Revista I beroamericana de Filosofía, Política y Humanidades, 6 (12), 83-91.

Maya Jariego, I. (2003). Conocimiento y patrones de utilización de servicios sociales de los inmigrantes africanos y asiáticos en la Costa del Sol. Revista de Servicios Sociales y Política Social, 62, 71-85.

Maya Jariego, I. (2003b). Pertinencia y accesibilidad de los servicios sociales para inmigrantes. En F. Checa, Arjona, A. y Checa, J.C. (Eds): La integración social de los inmigrados. Modelos y experiencias, pp. 323-345. Barcelona: Icaria Editorial.

Maya Jariego, I. A general typology of personal networks of immigrants with less than 10 years living in Spain. XXIII International Sunbelt Social Network Conference. Cancún (México), 14-17 de febrero de 2003c.

Maya Jariego, I. (2001). Sesgos de medida y problemas de muestreo en las encuestas de poblaciones inmigrantes. Metodología de Encuestas, 3 (2), 197-213.

Maya Jariego, I. Social Support Networks and Psychological Adaptation of African and Asian Immigrants in Spain. XXI International Sunbelt Social Network Conference. Budapest (Hungría), 25-28 de abril de 2001b.

Maya Jariego, I., Martínez, M. F., y García, M. (1999). Cadenas migratorias y redes de apoyo social de las mujeres peruanas en Sevilla. Demófilo: Revista de Cultura Tradicional de Andalucía, 29, 87-105.

Maya Jariego, I., Martínez, M. F., y García, M. (1997). Análisis bibliométrico de la investigación reciente en psicología sobre inmigración. Revista de Psicología Social Aplicada, 7 (1), pp. 69-83.

Maya Jariego, I. y Martínez, M.F. (2002). El estudio de la adaptación psicológica de los inmigrantes. Estrategias para aumentar la validez de la investigación con minorías étnicas. En F. Checa (Eds): Las migraciones a debate. De las teorías a las prácticas sociales. Pp. 121-161. Barcelona: Icaria Editorial.

Maya Jariego, I. y de la Vega, L. Levels of multiplexity and types of support providers: personal networks of Indian immigrants in Argentina. XXIV International Sunbelt Social Network Conference. Portorož (Eslovenia), 12-16 de mayo de 2004.

Maya Jariego, I., Santos, R., Vergara, E. \& Holgado, D. (2005). El análisis de las redes personales en el estudio de las comunidades de inmigrantes: un enfoque orientado a la intervención. Laboratorio de Redes Personales y Comunidades, 
REDES- Revista hispana para el análisis de redes sociales

Vol.17,\#13, Diciembre 2009

http: //revista-redes.rediris.es

Universidad de Sevilla. Estudio patrocinado por la Consejería de Gobernación de la Junta de Andalucía.

McCarty, C. (2002). Structure in Personal Networks. Journal of Social Structure, 3, $\# 1$.

McCarty, C. \& Molina, J. L. (2003). Egocentric Network Research Tool. Sunbelt XXIII, Cancún (México, Febrero de 2003).

Menjivar,C. (1997): Immigrant kinship networks: Vietnamese, Salvadoreans and Mexicans in comparative perspective. Journal of Comparative Family Studies, vol.28,1, 1-24.

Miller-Loncar,C.L., Erwin,L.J., Landry,S.H., Smith,K.E. y Swank,P.R. (1998): Characteristics of social support networks of low socioeconomic status african american, anglo american, and mexican american mothers of full-term and preterm infants. J ournal of Community Psychology, vol.26, no2, 131-143.

Morrison,G.M., Laughlin,J., San Miguel,S., Smith,D.C. y Widaman,K. (1997): Sources of support for school-related issues: choices of hispanic adolescents varying in migrant status. Journal of Youth and Adolescence, vol.26, 2, 233-252.

Palloni, A., Massey, D.S., Ceballos, M., Espinosa, K. y Spittel, M. (2001). Social Capital and International Migration: A Test Using Information on Family Networks. American Journal of Sociology, 106 (5), 1262-1298.

Schwarzer, R. y Hahn, A. (1995). Reemployment after migration from East to West Germany: A longitudinal study on psychosocial factors. Applied Psychology An International Review; Jan Vol 44(1) 77-93.

Sluzki, C. E. (1992): Disruption and reconstruction of networks following migration/relocation. Family Systems Medicine, Win Vol 10(4) 359-363.

Tonón, G. H. \& Maya Jariego, I. (2006). Comportamientos de apoyo, problemas percibidos y depresión en inmigrantes paraguayos y bolivianos en Argentina e inmigrantes marroquíes en España. En Maya Jariego, I., Holgado, D. \& Santolaya, F. J. (Ed.). Diversidad en el trabajo: estrategias de mediación intercultural. Sevilla: Multimedia de Mediación Intercultural, Fondo Social Europeo \& Junta de Andalucía. 